\title{
Modified Frailty as a Novel Factor in Predicting the Maintenance of the Sinus Rhythm After Electrical Cardioversion of Atrial Fibrillation in the Elderly Population
}

This article was published in the following Dove Press journal:

Clinical Interventions in Aging

\author{
Agnieszka Mlynarska (DD ${ }^{1,2}$ \\ Rafal Mlynarski $\mathbb{D}^{2,3}$ \\ Czeslaw Marcisz' \\ Krzysztof S Golba ${ }^{2,3}$ \\ 'Department of Gerontology and \\ Geriatric Nursing, School of Health \\ Sciences, Medical University of Silesia, \\ Katowice, Poland; ${ }^{2}$ Department of \\ Electrocardiology, Upper Silesian Heart \\ Centre, Katowice, Poland; ${ }^{3}$ Department \\ of Electrocardiology and Heart Failure, \\ School of Health Sciences, Medical \\ University of Silesia, Katowice, Poland
}

Introduction: Frailty is a common geriatric syndrome that causes an elevated risk of catastrophic declines in the health and function among older adults - we hypothesized that frailty may be related to the maintenance of sinus rhythm after cardioversion.

Methods: The study sample was a group of 199 consecutive patients over 60 (average age $71.41 \pm 6.99 ; 40.2 \%$ women) with AF who were hospitalized in order to perform electrical cardioversion. The Tilburg Frailty Indicator (TFI) was used to assess frailty before cardioversion. The six-month visit after the electrical cardioversion was a follow-up. The follow-up period for the maintenance of sinus rhythm after electrical cardioversion was $180 \pm 14$ days. Results: Patients in whom cardioversion was effective had a statistically significantly lower severity of frailty syndrome $(3.44 \pm 1.83$ vs $5.87 \pm 1.12 ; \mathrm{p}=0.000)$ and its components: physical components $(2.14 \pm 1.33$ vs $3.62 \pm 1.05 \mathrm{p}=0.000)$; emotional components $(0.92 \pm$ 0.79 vs $1.29 \pm 0.86 p=0.037)$ and social components $(0.37 \pm 0.56$ vs $0.96 \pm 0.46 ; p=0.000)$ compared to those patients in which cardioversion was ineffective. In the logistic regression, frailty (OR: $0.65,95 \%$ CI:0.5010-0.8330; $\mathrm{p}=0.000$ ) was observed to be an independent predictor for maintaining sinus rhythm.

Conclusion: Frailty is a novel, independent factor that can be used to predict the effectiveness of electrical cardioversion and the maintenance of sinus rhythm in the elderly population. Modifying the level of recognition in the Tilburg Frailty Indicator to a 4 improved the prediction of the effectiveness of electrical cardioversion as well as the maintenance of sinus rhythm.

Keywords: frailty, atrial fibrillation, electrical cardioversion, sinus rhythm

\section{Introduction}

Atrial fibrillation (AF), which occurs in $1-2 \%$ of the general population, is considered to be one of the epidemics of the 21 st century. It is estimated that nearly 400,000 people suffer from AF in Poland. With increasing age, the incidence of atrial fibrillation increases; it is estimated that in patients between 60 and 70 years old, it occurs in $4.2 \%$ of the population, while in individuals who are more than 80 years old, it increases to $17 \% .^{1-3}$ This is the most common arrhythmia in clinical practice, and it is found in about $30 \%$ of people who are hospitalized due to arrhythmias. An even greater increase in the prevalence of this disease in the population is forecasted. ${ }^{4}$
Correspondence: Agnieszka Mlynarska Department of Gerontology and Geriatric Nursing, Upper-Silesian Medical Centre, ul. Ziolowa 45/47, Katowice 40-635, Poland Fax +48322524098

Email mlynarska83@gmail.com 
According to the European Society of Cardiology (ESC) guidelines, restoring and maintaining sinus rhythm are an integral part of the procedure in AF. Therefore, it is best to moderate an arrhythmia as soon as it is detected. Currently, two strategies are recommended for managing a patient with AF: therapy to maintain the sinus rhythm and $\mathrm{AF}$ acceptance and treatment to control the ventricular rate. Electrical cardioversion is one of the recognized methods for treating atrial fibrillation $(\mathrm{AF}) /$ maintaining sinus rhythm. There are no unequivocal factors that permit the response to electrical cardioversion in the elderly population to be predicted. ${ }^{1,5}$

The guidelines for treating atrial fibrillation do not indicate any advantage of a rhythm-control strategy over a rate-control strategy in the elderly population. ${ }^{1}$ Because older patients experience more advanced structural and electrical remodeling of the atria, the rate of success in maintaining sinus rhythm in this age group may be worse. In addition, concomitant diseases, which may significantly limit the treatment options, are also more common in elderly patients. Therefore, elderly patients should initially be treated with a rate-control strategy. One of the factors that affects the success of atrial fibrillation therapy may be the coexistence of frailty syndrome. ${ }^{1,6}$ Frailty syndrome is a dynamic process that leads to a reduction in the physical, mental and/or social functions that are associated with the aging process. This condition is a potential public health problem due to its numerous clinical and social consequences and its dynamic nature. ${ }^{7-9}$ Frailty syndrome is defined as a clinically recognizable state of increased vulnerability that results from age-related decline in the reserve and function in many physiological systems and a limited ability to deal with daily or acute stressors. The appropriate identification of frailty syndrome can reduce the risk of potential interventions, ${ }^{8,10}$ and the dynamic nature of frailty emphasizes the potential for preventive and corrective interventions. ${ }^{11}$ After early detection, it is possible to maintain the functional and cognitive reserves, maintain self-care and prevent disabilities, falls, functional decline, institutionalization, hospitalization and death. ${ }^{7,8}$

Frailty is a common geriatric syndrome that causes an elevated risk of catastrophic declines in the health and function among older adults - we hypothesized that frailty could be a factor in predicting the effectiveness electrical cardioversion and maintenance of the sinus rhythm.

\section{Patients and Methods}

\section{Study Design and Settings}

This was an observational - prospective study, which was conducted in the Department of Electrocardiology and Heart Failure.

\section{Study Participants and Selection}

The study sample was a group of 199 consecutive patients over 60 (average age $71.41 \pm 6.99 ; 40.2 \%$ women) with AF who were hospitalized in the Department of Electrocardiology and Heart Failure in the years 2015-2017 in order to perform electrical cardioversion. Patients with permanent atrial fibrillation or without proper anticoagulation during the four weeks prior cardioversion or those who had a thrombus or echogenic blood in the left atrium were excluded. Patients with diagnosed cancer in the active phase were also excluded. Twenty-one patients were excluded from the due to their refusal to participate in the follow-up visit during the study.

The optimal pharmacological treatment of the existing cardiovascular diseases was confirmed in all of the included patients. All of the patients underwent a standard physical examination, a 12-lead electrocardiogram and echocardiography. During the biphasic cardioversion, a standard energy of two joules per kg were used. Effectiveness of the electrical cardioversion was defined as sinus rhythm presence directly after cardioversion meanwhile maintenance of sinus rhythm at 6 months, being in sinus rhythm without need of electrical cardioversion during that time.

\section{Ethical Considerations}

The Medical University of Silesia ethics committee approved the study protocol (KNW/0022/KB/20/19). The study protocol complied with the version of the Helsinki Convention that was current at the time the study was designed. Participation in this study was anonymous and voluntary. All of the participants gave their written consent at the beginning of the study and were also informed about its purpose and of the possibility to withdraw their participation at any stage.

\section{Research Instruments}

The Tilburg Frailty Indicator (TFI) was used to assess frailty before cardioversion. This is a tool that was developed by Gobbens et al that is based on the concept of the frailty model. The scale consists of two parts: part A, 
which concerns the determinants of frailty syndrome and part $\mathrm{B}$, which includes 15 questions on the presence of the components of frailty. The first eight questions are for the physical component, the next four questions are for the emotional component and the last three questions are for the social component. The total TFI value is within a range of 0 to 15 points, and frailty syndrome is recognized as 5 points and above. The higher the score, the higher the level of frailty syndrome. ${ }^{10,11}$

\section{Follow-Up}

The six-month visit after electrical cardioversion was a follow-up. The follow-up period for maintaining sinus rhythm after electrical cardioversion was $180 \pm 14$ days.

\section{Statistical Analyses}

The Shapiro-Wilk test was used to check the normality of the data distribution. The two groups were compared using the Student's $t$-test for the normal distribution of the variable, while groups without a normal distribution were analyzed using the Mann-Whitney test. The chi $^{2}$ test and chi $^{2}$ test with the Yates correction were used for the selected nonparametric data. Univariate logistic regression analysis was also used to predict the factors that were associated with the effectiveness of electrical cardioversion and maintaining sinus rhythm. A receiver operating characteristic (ROC) curve analysis was used to evaluate the diagnostic performance of frailty syndrome. The area under the curve was calculated to reflect and to compare the predictive value of frailty syndrome in order to discriminate the patients who had an effective electrical cardioversion and maintenance of sinus rhythm. The results were considered to be significant at $\mathrm{P}$ values $<0.05$. All of the presented analyses were performed using MedCalc (MedCalc Software, Ostend, Belgium).

\section{Results}

The characteristics of the patients that were included in the study are presented in Table 1. Effective electrical cardioversion was observed in 174 patients of the 199 patients (87.4\%). In this group, electrical cardioversion was effective in $64(80 \%)$ of the women and $110(92.4 \%)$ of the men; $\mathrm{p}=0.094$. Frailty was recognized in 68 of the 199 patients $(34.17 \%)$. Frailty syndrome was diagnosed in the women more often (37) (46.25\%) compared to the men (34) (28.2\%); $\mathrm{p}=0.032$. None of the patients had complications

Table I Characteristics of the Patients That Were Included in the Study

\begin{tabular}{|c|c|c|c|c|}
\hline & $\begin{array}{l}\text { All } \\
n=199\end{array}$ & $\begin{array}{l}\text { Frailty } \\
n=68\end{array}$ & $\begin{array}{l}\text { Robust } \\
n=|3|\end{array}$ & $\mathbf{p}$ \\
\hline Age & $71.41 \pm 6.99$ & $74.44 \pm 6.95$ & $69.83 \pm 6.50$ & 0.000 \\
\hline Gender [women] & $40.2 \%$ & $54.41 \%$ & $32.82 \%$ & 0.003 \\
\hline Weight $[\mathrm{kg}]$ & $83.37 \pm 15.66$ & $80.14 \pm 16.30$ & $84.97 \pm 14.85$ & 0.051 \\
\hline Height $[\mathrm{cm}]$ & $67.38 \pm 9.62$ & $165.00 \pm 9.33$ & $168.56 \pm 9.59$ & 0.019 \\
\hline \multicolumn{5}{|l|}{ EHRA } \\
\hline I & $20.10 \%$ & $5.88 \%$ & $27.48 \%$ & 0.043 \\
\hline 2 & $43.22 \%$ & $20.59 \%$ & $54.96 \%$ & \\
\hline $2 b$ & $15.58 \%$ & $22.06 \%$ & $12.21 \%$ & \\
\hline 3 & $20.10 \%$ & $48.53 \%$ & $5.34 \%$ & \\
\hline 4 & $1.01 \%$ & $2.90 \%$ & $0 \%$ & \\
\hline Hypertension [yes] & $79.39 \%$ & $85.29 \%$ & $76.36 \%$ & 0.138 \\
\hline Diabetes [yes] & $19.09 \%$ & $27.94 \%$ & $14.50 \%$ & 0.000 \\
\hline Peripheral Artery Disease [yes] & $55.78 \%$ & $61.76 \%$ & $52.67 \%$ & 0.579 \\
\hline $\mathrm{CHA}_{2} \mathrm{DS}_{2} \mathrm{VASC}$ & $3.54 \pm 1.46$ & $4.47 \pm 1.36$ & $3.05 \pm 1.26$ & 0.000 \\
\hline Creatinine $[\mathrm{mg} / \mathrm{dl}]$ & $1.08 \pm 0.44$ & $1.01 \pm 0.23$ & $1.12 \pm 0.51$ & 0.073 \\
\hline Ejection fraction [\%] & $52.74 \pm 11.08$ & $54.37 \pm 10.69$ & $51.87 \pm 11.22$ & 0.134 \\
\hline Left atrium area $\left[\mathrm{cm}^{2}\right]$ & $26.42 \pm 5.16$ & $26.13 \pm 4.93$ & $26.57 \pm 1.15$ & 0.572 \\
\hline Left atrium diameter & $44.49 \pm 5.46$ & $44.40 \pm 5.14$ & $44.55 \pm 5.64$ & 0.863 \\
\hline NOAC & $38.69 \%$ & $29.41 \%$ & $43.51 \% \%$ & 0.053 \\
\hline VKA & $59.29 \%$ & $66.18 \%$ & $55.72 \%$ & 0.155 \\
\hline Other & $2.02 \%$ & $4.41 \%$ & $0.77 \%$ & 0.227 \\
\hline
\end{tabular}

Abbreviations: EHRA, European Heart Rhythm Association; NOAC, novel oral anticoagulants; VKA, vitamin K antagonists; Other, eg enoxaparin. 
Table 2 Gender-Related Values of Frailty Syndrome and the Individual Domains

\begin{tabular}{|c|c|c|c|c|}
\hline & $\begin{array}{l}\text { Whole Group } \\
\text { Mean; SD } \\
\text { Min - Max } \\
\text { n=199 }\end{array}$ & $\begin{array}{l}\text { Men } \\
\text { Mean; SD } \\
\text { Min - Max } \\
\mathrm{n}=1 \text { 19 }\end{array}$ & $\begin{array}{l}\text { Women } \\
\text { Mean; SD } \\
\text { Min - Max } \\
n=80\end{array}$ & $\mathbf{p}$ \\
\hline Total frailty & $\begin{array}{l}3.73 \pm 1.93 \\
0-8\end{array}$ & $\begin{array}{l}3.34 \pm 1.94 \\
0-8\end{array}$ & $\begin{array}{l}4.31 \pm 1.94 \\
0-8\end{array}$ & 0.000 \\
\hline Physical components & $\begin{array}{l}2.32 \pm 1.39 \\
0-6\end{array}$ & $\begin{array}{l}2.14 \pm 1.40 \\
0-5\end{array}$ & $\begin{array}{l}2.59 \pm 1.40 \\
0-6\end{array}$ & 0.026 \\
\hline Emotional components & $\begin{array}{l}0.97 \pm 0.81 \\
0-3\end{array}$ & $\begin{array}{l}0.82 \pm 0.75 \\
0-3\end{array}$ & $\begin{array}{l}1.19 \pm 0.84 \\
0-3\end{array}$ & 0.002 \\
\hline Social components & $\begin{array}{l}0.44 \pm 0.58 \\
0-3\end{array}$ & $\begin{array}{l}0.38 \pm 0.54 \\
0-2\end{array}$ & $\begin{array}{l}0.54 \pm 0.64 \\
0-3\end{array}$ & 0.058 \\
\hline
\end{tabular}

such as a stroke/TIA (transient ischemic attack) after cardioversion. Most of the patients (183) (92\%) used B-blockers, and the second most frequent group of drugs were potassium channel blockers and (52) (26\%) of patients used calcium channel blockers. Cardioversion after the first shock was successful in $183(92 \%)$ of the patients. The detailed characteristics regarding the occurrence of frailty syndrome are presented in Table 2.

The patients for whom cardioversion was effective showed a significantly lower severity of frailty syndrome $(3.44 \pm 1.83$ vs $5.87 \pm 1.12 ; \mathrm{p}=0.000)$ and its components: physical components $(2.14 \pm 1.33$ vs $3.62 \pm 1.05 \mathrm{p}=0.000)$; emotional components $(0.92 \pm 0.79$ vs $1.29 \pm 0.86$ $\mathrm{p}=0.037)$ and social components $(0.37 \pm 0.56$ vs $0.96 \pm$ $0.46 ; \mathrm{p}=0.000)$ compared to those patients for which cardioversion was ineffective.

An analysis of sinus rhythm maintenance after sixmonth of follow-up showed that the group of patients with a maintained sinus rhythm had a significantly lower severity of frailty syndrome $(3.55 \pm 1.91$ vs $5.04 \pm 1.63$; $\mathrm{p}=0.000)$ and its components: physical components $(2.21$ \pm 1.36 vs $3.17 \pm 1.31 ; \mathrm{p}=0.001)$ and social components $(0.39 \pm 0.57$ vs $0.79 \pm 0.59 ; \mathrm{p}=0.002)$. We found significant difference in the values for the emotional scale $(0.95$ \pm 0.81 vs $1.08 \pm 0.78 ; \mathrm{p}=0.465)$.

The effectiveness of cardioversion in the frailtyaffected group was $66.2 \%$ (45/68), whereas it was $99.2 \%$ $(130 / 131)$ in the robust group; $p=0.000$. In the women with diagnosed frailty syndrome, the effectiveness of cardioversion was $59.5 \%$ and $100 \%$ of cardioversion was effective in the robust women. A similar situation was observed in the group of men, in the men with frailty syndrome, cardioversion effectiveness was $74.2 \%$, while in the robust patients, it was $98.9 \%$.

Most of the patients $(87.9 \%)$ had maintained sinus rhythm after six months. In the frailty-affected group, it was $75 \%$ vs $94.6 \%$ in the robust group; $p=0.000$. Sinus rhythm was maintained in all of the women in the robust group but in only $54.1 \%$ of the women with diagnosed frailty syndrome. In the men, the difference between maintaining sinus rhythm that was dependent on the occurrence of frailty syndrome was smaller $-94.3 \%$ of the robust men and $80.64 \%$ of the men with diagnosed frailty syndrome had maintained sinus rhythm after six months.

In the logistic regression, which had been adjusted to age and gender, frailty (OR: 0.41, 95\% CI:0.2870-0.5851; $\mathrm{p}<0.000$; Nagelkerke $R^{2}=0.33$ ) was an independent predictor of the effectiveness of electrical cardioversion. The ROC curves for frailty in the effectiveness electrical cardioversion are presented in Figure 1. The area under the curve was $0.856(95 \% \mathrm{CI}-0.799-0.902)$. The cutoff value for recognizing frailty was $4(\mathrm{p}<0.000)$. Similarly, in the univariate logistic regression, which had been adjusted to age and gender, frailty (OR: 0.65, 95\% CI:0.5010-0.8330; $\mathrm{p}=0.000$; Nagelkerke $R^{2}=0.12$ ) was also an independent predictor for maintaining sinus rhythm. The ROC curves for frailty in maintaining sinus rhythm are presented in Figure 2. The area under the curve is 0.718 (95\% CI $0.650-0.779)$. The cutoff value for recognizing frailty, in this case, was also $4(\mathrm{p}<0.000)$.

\section{Discussion}

Atrial fibrillation very often affects the elderly. Bunch et al proved that AF was independently associated with all 


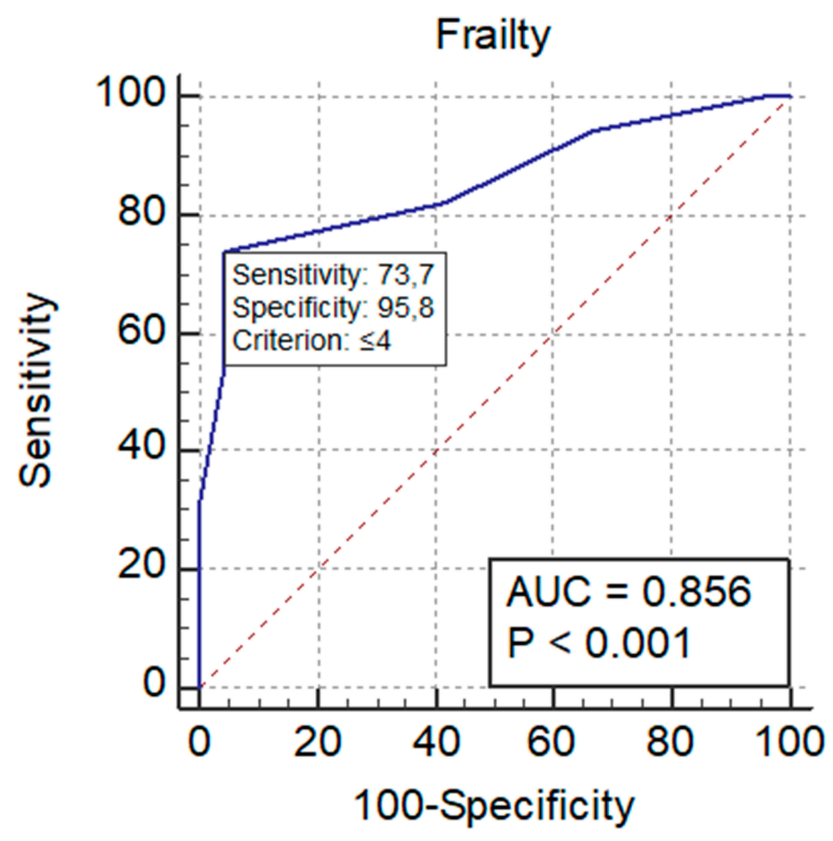

Figure I The ROC curves for frailty in the effectiveness of electrical cardioversion.

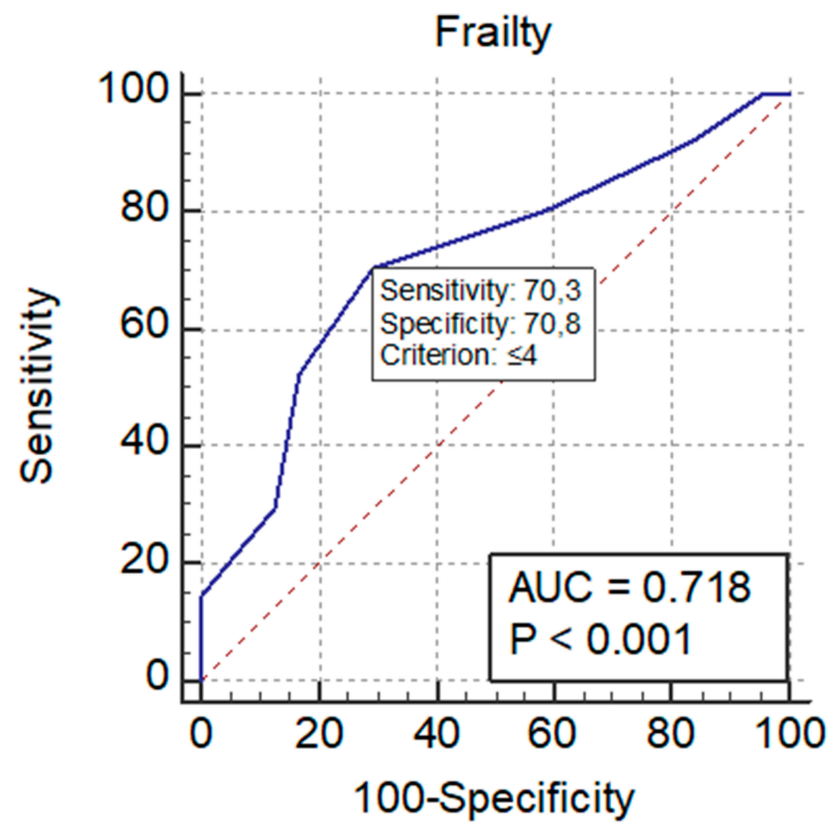

Figure 2 The ROC curves for frailty in the maintenance of sinus rhythm.

forms of dementia. ${ }^{12}$ Some geriatric-dependent diseases are described as being the reasons for not prescribing oral anticoagulants, which suggests that prescribers may either be unaware of or deliberately ignoring the presence of these factors in clinical settings. ${ }^{13}$ Meanwhile, the study of Nguyen et al suggested that the frailty status had little impact on antithrombotic prescriptions and also had no impact on anti-arrhythmic prescriptions. ${ }^{14}$ One of the biggest problems in modern geriatrics is frailty syndrome, which is often mistakenly identified with multiple diseases. Frailty syndrome is a state of increased susceptibility to endogenous and exogenous stress factors, which result from reduced physiological reserves and the dysfunction of many of the systems that affect homeostasis and the stress response. ${ }^{15,16}$

The literature reports that frailty syndrome is diagnosed in $4.4 \%$ to $75.4 \%$ of patients with atrial fibrillation. Polidoro et al showed that frailty is an independent factor that is associated with prevalent AF (AF: $89 \%$ frail vs no AF: $67 \%$ frail). In our study, we identified frailty syndrome in $34.2 \%$ of patients, and more often among the women. ${ }^{17,18}$

Many authors have undertaken research whose aim was to assess the factors that affect the effectiveness of electrical cardioversion. Among the factors that influence the effectiveness of cardioversion are the elimination of the cause of arrhythmias, the duration of arrhythmia, age, obesity, mitral valve defects, left atrial enlargement, number of previous relapses, atrial conduction disturbances and a higher heart rate. A number of researches also lists the echocardiographic factors that are conducive to the recurrence of arrhythmia, among which the size and function of the left atrium and its appendix are the most important. ${ }^{19-21}$ There is also a need to explain fact that AF recurrence rates after electrical cardioversion are ranging from $63 \%$ to $84 \%$ in the first year, meanwhile according to our results $87.9 \%$ of the patients had maintained sinus rhythm after six months. We believe this is related to the specific population. In our case, prior to their recruitment for the study, the patients were being treated by a cardiologist and were receiving the appropriate antiarrhythmic treatment, which had been adjusted according to their age and abilities.

However, among these numerous studies, no impact analysis of the effect of frailty syndrome on the effectiveness of electrical cardioversion and the maintenance of sinus rhythm has been undertaken. According to the adopted definition of frailty syndrome, this is a geriatric syndrome that is characterized by a reduction in the reserves and resistance to stressors, which result from the accumulation of the decreased efficiency of various physiological systems, which in turn leads to a susceptibility for the occurrence of some adverse consequences. A reduction in the reserves, a lack of resistance to stressors and a reduced efficiency of the physiological reserves may result in the ineffectiveness 
of cardioversion and an inability to maintain sinus rhythm after successful electrical cardioversion. ${ }^{22}$

The results of a European Heart Rhythm Association survey showed that $40 \%$ of the centers believed that a ratecontrol strategy was the best approach for frail patients with AF, whereas $57.1 \%$ of the centers believed that both the rate-control and rhythm-control strategy could be used depending on the clinical context. ${ }^{23}$

Assessing the occurrence of frailty syndrome before elective electrical cardioversion could be an element in deciding whether to perform cardioversion and the treatment strategy to be used. Elderly patients who are already at risk of frailty syndrome or are prefrail are at risk of cardioversion failure and a lack of maintaining sinus rhythm at a 180-day follow-up. According to our results, modifying of the value on the Tilburg Frailty Indicator to 4 points (typical value is 5 points) for patients with atrial fibrillation may be one of the reasons for the lack of treatment effectiveness and a predictor for recommending those patients for increased care and a comprehensive holistic geriatric assessment. Our results are in agreement with Lefebvre et al, who suggested that frailty syndrome should be assessed for all patients with diagnosed atrial fibrillation. $^{24,25}$ Our results, combined with those of Conkbayir et al, who believe that restoring and maintaining sinus rhythm seem to have a beneficial effect on the secondary prevention of stroke in patients with AF, may cautiously confirm the general belief of clinicians that it is necessary to restore sinus rhythm and its maintenance in all patients but perhaps especially in the elderly. ${ }^{26}$

\section{Conclusion}

Frailty is a novel, independent factor that can be used in predicting the effectiveness of electrical cardioversion and the maintenance of sinus rhythm in the elderly population. Modifying the level of recognition in the Tilburg Frailty Indicator to a 4 improved the prediction of the effectiveness of electrical cardioversion as well as the maintenance of sinus rhythm.

\section{Study Limitations}

The most important limitation of this research is the fact that our study sample was recruited from a single center.

\section{Acknowledgment}

An abstract of this paper was presented at the ESC Congress 2019 and Expo as a poster presentation with interim findings $\mathrm{P}_{1906 .}{ }^{27}$

\section{Funding}

The research was funded by Medical University of Silesia, grant number KNW-1-043/N/9/Z.

\section{Disclosure}

The abstract of this paper was presented at ESC Congress 2019 and Expo as a poster presentation with interim findings. The poster's abstract was published in "Poster Abstracts" in European Heart Journal, Volume 40, Issue Supplement_1, October 2019, ehz748.0653, https://doi.10. 1093/eurheartj/ehz748.0653. The authors report no conflicts of interest in this work.

\section{References}

1. Kirchhof P, Benussi S, Kotecha D, et al. ESC scientific document group. 2016 ESC guidelines for the management of atrial fibrillation developed in collaboration with EACTS. Eur Heart J. 2016;37: 2893-2962. doi:10.1093/eurheartj/ehw210

2. Głuszak A, Kocoń S, Zuk K, Aljabali P, Gluza A, Siwek K. Episodes of atrial fibrillation and meteorological conditions. Kardiol Pol. 2008;66:958-962.

3. Wilkinson C, Todd O, Clegg A, Gale C, Hall M. Management of atrial fibrillation for older people with frailty: a systematic review and meta-analysis. Age Ageing. 2019;48:196-203. doi:10.1093/ageing/afy180

4. Wattigney W, Mensah G, Croft J. Increasing trends in hospitalization for atrial fibrillation in the United States, 1985 through 1999: implications for primary prevention. Circulation. 2003;108:711-716. doi:10.1161/01.CIR.0000083722.42033.0A

5. de Denus S, Sanoski C, Carlsson J, Opolski G, Spinler S. Rate vs rhythm control in patients with atrial fibrillation: a meta-analysis. Arch Intern Med. 2005;165:258-262. doi:10.1001/archinte.165.3.258

6. Curtis A, Karki R, Hattoum A, Sharma U. Arrhythmias in patients $\geq 80$ years of age: pathophysiology, management, and outcomes. $J \mathrm{Am}$ Coll Cardiol. 2018;71:2041-2057. doi:10.1016/j.jacc.2018.03.019

7. Faller J, Pereira D, de Souza S, Nampo F, Orlandi F, Matumoto S. Instruments for the detection of frailty syndrome in older adults: a systematic review. PLoS One. 2019;14:e216166. doi:10.1371/journal.pone. 0216166

8. Xue QL. The frailty syndrome: definition and natural history. Clin Geriatr Med. 2011;27:1-15. doi:10.1016/j.cger.2010.08.009

9. Buckinx F, Rolland Y, Reginster J, Ricour C, Petermans J, Bruyère O. Burden of frailty in the elderly population: perspectives for a public health challenge. Arch Public Health. 2015;73:19. doi:10.1186/ s13690-015-0068-x

10. Gobbens RJ, van Assen MA, Luijkx KG, Wijnen-Sponselee MT, Schols JM. The Tilburg Frailty Indicator: psychometric properties. $J$ Am Med Dir Assoc. 2010;11:344-355.

11. Uchmanowicz I, Gobbens R, Jankowska-Polanska B, ŁobozRudnicka M,Manulik S, Łoboz-Grudzień K. Cross-cultural adaptation and reliabilitytesting of the Tilburg frailty indicator for optimizing care of Polishpatients with frailty syndrome. Clin Interv Aging. 2014;9:997-1001

12. Bunch T, Weiss J, Crandall B, et al. Atrial fibrillation is independently associated with senile, vascular, and Alzheimer's dementia. Heart Rhythm. 2010;7:433-437. doi:10.1016/j.hrthm.2009.12.004

13. Saczynski J, Sanghai S, Kiefe C, et al. Geriatric elements and oral anticoagulant prescribing in older atrial fibrillation patients: SAGE-AF. J Am Geriatr Soc. 2020;68:147-154. doi:10.1111/jgs.16 178 
14. Nguyen T, Cumming R, Hilmer S. Atrial fibrillation in older inpatients: are there any differences in clinical characteristics and pharmacological treatment between the frail and the non-frail? Intern Med J. 2016;46:86-95. doi:10.1111/imj.12912

15. Mlynarska A, Mlynarski R, Golba K. Frailty syndrome in patients with heart rhythm disorders. Geriatr Gerontol Int. 2017;17: 1313-1318. doi:10.1111/ggi.12868

16. Mlynarska A, Mlynarski R, Golba K. Anxiety, age, education and activities of daily living as predictive factors of the occurrence of frailty syndrome in patients with heart rhythm disorders. Aging Ment Health. 2018;22:1179-1183. doi:10.1080/13607863.2017.1348468

17. Polidoro A, Stefanelli F, Ciacciarelli M, Pacelli A, Di Sanzo D, Alessandri C. Frailty in patients affected by atrial fibrillation. Arch Gerontol Geriatr. 2013;57:325-327. doi:10.1016/j.archger.2013.04. 014

18. Zathar Z, Karunatilleke A, Fawzy A, Lip G. Atrial fibrillation in older people: concepts and controversies. Front Med. 2019;6:175. doi: $10.3389 /$ fmed.2019.00175

19. Brodsky M, Allen B, Capparelli E, Luckett C, Morton R, Henry W. Factors determining maintenance of sinus rhythm after chronic atrial fibrillation with left atrial dilatation. Am J Cardiol. 1989;63:1065-1068. doi:10.1016/0002-9149(89)90079-9

20. Marchese P, Malavasi V, Rossi L, et al. Indexed left atrial volume is superior to left atrial diameter in predicting nonvalvular atrial fibrillation recurrence after successful cardioversion: a prospective study. Echocardiography. 2012;29:276-284. doi:10.1111/j.1540-8175.2011. 01580.x
21. Omran H, Jung W, Schimpf R, et al. Echocardiographic parameters for predicting maintenance of sinus rhythm after internal atrial defibrillation. Am J Cardiol. 1998;81:1446-1449. doi:10.1016/ S0002-9149(98)00212-4

22. Fried L, Tangen C, Walston J, et al. Frailty in older adults: evidence for a phenotype. J Gerontol a Biol Sci Med Sci. 2001;56:46-56. doi:10.1093/gerona/56.3.M146

23. Fumagalli S, Potpara T, Larsen T, et al. Frailty syndrome: an emerging clinical problem in the everyday management of clinical arrhythmias. The results of the European Heart Rhythm Association survey. EP Europace. 2017;19:1896-1902. doi:10.1093/europace/ eux 288

24. Lefebvre M, St-Onge M, Glazer-Cavanagh M, et al. The effect of bleeding risk and frailty status on anticoagulation patterns in octogenarians with atrial fibrillation: the FRAIL-AF study. Can J Cardiol. 2016;32:169-176. doi:10.1016/j.cjca.2015.05.012

25. Bibas L, Levi M, Touchette J, et al. Implications of frailty in elderly patients with electrophysiological conditions. JACC Clin Electrophysiol. 2016;2:288-294. doi:10.1016/j.jacep.2016.04.013

26. Conkbayir C, Yigit Z, Hural R, et al. Do restoring and maintaining sinus rhythm have a beneficial effect on secondary prevention of stroke in patients with atrial fibrillation? A pilot study. Angiology. 2019;70:916-920. doi:10.1177/0003319719856455

27. Mlynarska A, Mlynarski R, Marcisz C, Golba KS. Modified frailty as a novel factor to predict the effectiveness of electrical cardioversion of atrial fibrillation in the elderly population. Eur Heart J. 2019;40: P1906. doi:10.1093/eurheartj/ehz748.0653
Clinical Interventions in Aging

\section{Publish your work in this journal}

Clinical Interventions in Aging is an international, peer-reviewed journal focusing on evidence-based reports on the value or lack thereof of treatments intended to prevent or delay the onset of maladaptive correlates of aging in human beings. This journal is indexed on PubMed Central, MedLine, CAS, Scopus and the Elsevie
Bibliographic databases. The manuscript management system is completely online and includes a very quick and fair peer-review system, which is all easy to use. Visit http://www.dovepress.com/ testimonials.php to read real quotes from published authors. 